\title{
A CHEMICAL STUDY OF MINT OIL
}

N. M. Solodovnichenko

Khimiya Prirodnykh Soedinenii, Vol. 6, No. 1, p. 136, 1970

UDC 547.913.582.949.633.822

We have previously established [1] that in the production of mint oil the still residue contains a considerable amount of high-boiling substances. From the fraction with bp $118-121^{\circ} \mathrm{C} / 5 \mathrm{~mm}$ by separation on alkaline alumina (activity grade III) with subsequent purification on silica gel (eluant, $n$-hexane) we have isolated a yellow substance with a weak aromatic odor having bp $125-126^{\circ} \mathrm{C} / 8 \mathrm{~mm} ; \mathrm{d}_{20}^{20} 0.9039 ; \mathrm{n}_{\mathrm{D}}^{20} 1.4997,[\alpha]_{\mathrm{D}}^{20}-7.1^{\circ}$; nitrosochloride with mp 158-159 $\mathrm{C}$; dihydrochloride with $\operatorname{mp} 60-70^{\circ} \mathrm{C}$. The substance was identified as $\beta$-caryophyllene [2].

A fraction with bp $125-130^{\circ} \mathrm{C} / 5 \mathrm{~mm}$ gave an intense violet color with a solution of bromine in chlor oform [3], and with the Ehrlich-Müller reagent [4] it gave a blue-violet color. After thrice-repeated chromatography on alkaline alumina, a substance was obtained with a faint yellow color and a weak aromatic odor having bp $130-131^{\circ} \mathrm{C} / 9 \mathrm{~mm}$; $\mathrm{d}_{20}^{20} 0.9249 ; \mathrm{n}_{\mathrm{D}}^{20} 1.5065 ;[\alpha]_{\mathrm{D}}^{20}+20.0^{\circ} ; \mathrm{MR} 65.78 ; \mathrm{C}_{15} \mathrm{H}_{24}$.

The hydrogenation product had bp $107-108^{\circ} \mathrm{C} / 5 \mathrm{~mm} ; \mathrm{d}_{20}^{20} 0.8917 ; \mathrm{n}_{\mathrm{D}}^{20} 1.4827$; and the dehydrogenation product (a blue azulene), $\mathrm{mp}$ of TNB derivative $149-150^{\circ} \mathrm{B}$ (Kofler block), mp of TNT derivative $89^{\circ} \mathrm{C}$. The physical properties of the compound isolated are close to those of guaiene [5]. Their IR absorption spectra and those of the hydrogenation products (guaiane) and dehydration products coincide completely.

The azulene is identical with S-guaiazulene [6] (chromatography with an authentic sample, IR spectra).

\section{R E F E R E N E S}

1. N. M. Solodovnichenko and Yu. G. Borisyuk, Farm. zh. , no. 2, 44, 1962.

2. G. V. Makarova, Tr. Khar'kovskogo gosfarminstituta, Khar'kov, no. 1, 244, 1957.

3. S. Sabetay and H. Sabetay, Compt. rend Acad. Sci. , 199, 313, 1934.

4. A. Müller, J. f. prakt. Chem., 151, no. 9-12, 233, 1938.

5. J. Pliva, N. Horak, V. Herout, and F. Sorm, Die Terpene Sammlung von spektren und physikalischen Eigenschaften, Berlin, Akademie Verl. I, 1960.

6. F. Sorm, A. Mlesiva, Z. Arnold, and J. Pliva, Collect. czechosl. chem. commun. , 14, $699,1949$.

8 July 1969

Khar'kov Pharmaceutical Institute 